\title{
Urban Heat Island: Causes, Effects and Mitigation Measures - A Review
}

\author{
Md. Nuruzzaman \\ Department of Civil Engineering, Rangpur Engineering College, Rangpur, Bangladesh \\ Email address: \\ mnz_ruet@yahoo.com \\ To cite this article: \\ Md. Nuruzzaman. Urban Heat Island: Causes, Effects and Mitigation Measures - A Review. International Journal of Environmental \\ Monitoring and Analysis. Vol. 3, No. 2, 2015, pp. 67-73. doi: 10.11648/j.ijema.20150302.15
}

\begin{abstract}
High temperature in the city centers than its' surroundings known as the Urban Heat Island (UHI) effect, which is causing discomfort to the urban dwellers in the summer time is gaining much attention around the world because the world is getting urbanized as it advances in technology. Alterations of surface area, improper urban planning, air pollution, etc. are causing this increasingly growing phenomenon and it is accountable for human discomfort, human casualties and decline of climate. In this paper, an attempt has been taken to review various measures to encounter UHI effect and the processes by which these strategies work is described with diagrams. Using high albedo materials and pavements, green vegetation and green roofs, urban planning, pervious pavements, shade trees and existence of water bodies in city areas are the potential UHI mitigation strategies on which discussion is done in this paper with their limitations. Green vegetation seems to be the most effective measure and other strategies can play a major role under proper condition.
\end{abstract}

Keywords: Urban Heat Island, Causes, Effects, Mitigation Measures

\section{Introduction}

In most of the large cities, the temperature at the heart or the center of the city is noted to be higher than its surroundings or the suburban area. The phenomenon is called Urban Heat Island (UHI) effect (Adinna et al. 2009; Synnefa et al. 2008). In other words, cities demonstrate greater temperature in its center than the surrounding rural areas, which is known as Urban Heat Island effect (Yamamoto 2006). There forms a temperature difference between the cities and the surrounding suburbs because of the effect (Yamamoto 2006) which causes discomfort to the city dwellers. When a huge amount of natural land is replaced by artificial built surface that absorbs incoming solar radiation or heat and re-radiate it at night, it develops (Oke 1982 and Quattrochi et al. 2000). The fact is the case that the phenomenon exists in almost every big city (Yamamoto 2006). Numerous factors are held accountable for this effect, including anthropogenic heat release, surface cover, climatic conditions, air pollutants, etc. (Yamamoto 2006). According to Oke, T.R. (1982) under proper conditions, UHI may be up to $10-15^{\circ} \mathrm{C}$. As a consequence of the microclimate created by the UHI, the demand for energy to cool buildings increases (Adina et al. 2009). Furthermore, to meet the demand, more generation of power is needed, which results increased amount of greenhouse gases emission and decline of climate. One of the vital reasons for the formation of UHI is the large amount of built up surfaces like concrete, asphalt which has a high heat capacity (Akbari et al. 2001). Low albedo materials are further contributing to worsening the phenomenon. According to Taha (1997), when non reflective and waterresistant, impervious materials at the surface takes the place of natural vegetation, Urban Heat Island is created. It is a process which varies with the built regions and geographical conditions of a metropolitan area (Grimmond \& Oke 1999). Another reason to exacerbate the Urban Heat Island effect is improper planning of cities (Li, K. et al.) Taha, H. (1997) says air pollutants from industrial processes, power plants, exhaust gases from the vehicles and anthropogenic heat may add to the intensity of UHI effect. According to Akbari et al. (2001) the demand for electricity rises up from $2-4 \%$ for every $1^{0} \mathrm{C}$ rise in temperature. In a typical urban area, surfaces are darker and vegetation is less than its surroundings. The temperature difference of a typical city with its' surrounding rural areas may be as much as $2.5^{\circ} \mathrm{C}$ in a warm summer daytime, which may cause for additional 5-10\% municipal peak electricity demand (Akbari et al. (2001). However, in the winter season, as it is cold in the environment, the UHI effect plays a positive role for the city dwellers by providing them with warm air (Shahmohamadi 2010; Voogt 2004; Mobaraki 2012). However, 
it has a negative effect in the summertime on the comfort of human health and energy consumption both at day and night.

\section{Causes of Urban Heat Island and Its Effects}

\subsection{Causes}

According to Santamouris et al. (2007); Akbari et al. (2001) and Oke (1987) the following are the causes of UHI:

- Low amount of evapotranspiration because of less vegetation

- Absorption of solar radiation due to low albedo

- Hindrance to the flow of air because of higher rugosity

- High amount of anthropogenic heat release

However, there are a number of factors which contribute to the formation of Urban Heat Island. The factors which play a significant role in the creation of UHI are described below.

\subsubsection{Low Albedo Materials}

According to Bouyer (2009), albedo is evaluated by the ratio of the reflected solar energy to the incident solar energy. It depends on the arrangement of surfaces, materials, pavements, coatings, etc. Albedo has a direct impact on the formation of the microclimate. The albedo of a city varies according to various factors like surface arrangement i.e. orientation, heterogeneity; materials for roofs, pavements etc. (Bouyer et al. 2009). If the albedo of the urban surface is low, it will store more solar energy and the effect will be increasing of urban temperature i.e. creation of the urban microclimate.

\subsubsection{Human Gathering}

As the human gathering is prominent at the city centers owing to the availability of various facilities, emission of $\mathrm{CO}_{2}$ is also huge in these areas. $\mathrm{CO}_{2}$ stores heat, causing enhanced atmospheric temperature. The ultimate effect is that it assists in the formation of heat island to a great extent.

\subsubsection{Increased Use of Air Conditioner}

To provide comfort to the human beings at summertime, air conditioner is massively used with a rising trend. Air conditioners keep a building cool inside, but release the heat absorbing from inside to the atmosphere (Okwen 2011). As a consequence, the outside environment is warmed leading to the increasing of atmospheric temperature.

\subsubsection{Destruction of Trees}

To meet the demand of various urban facilities, forests are wiped out in a massive scale. Lesser trees means less cooling efficiency. Trees intercept the solar heat and also absorb $\mathrm{CO}_{2}$ for their own photosynthesis, making the environment cool (Akbari et al. 2001). With the destruction of plant life, the efficiency of cooling system goes radically down, causing creation of the process.

\subsubsection{Urban Canopy}

In urban areas, there are multilayer buildings. The heat reflected by a building is trapped by the nearby taller buildings which is known as the urban canopy (Masson 2006). UHI is exacerbated with the formation of urban canopy.

\subsubsection{Wind Blocking}

Due to the presence of densely situated buildings, wind velocity is reduced. As a result, the cooling effect by convection lessens. So, the heat trapped, cannot be blown out, resulting intensification of the effect (Priyadarsini 2008).

\subsubsection{Air Pollutants}

In the urban areas, especially in the city centers, air pollution is eminent. Exhaust gases from vehicles and industrial pollutants released in the environment, trap solar radiation (Bose 2009). Thus, the temperature rises and the microclimate effect becomes stronger.

The causes are summarized in the following figure:

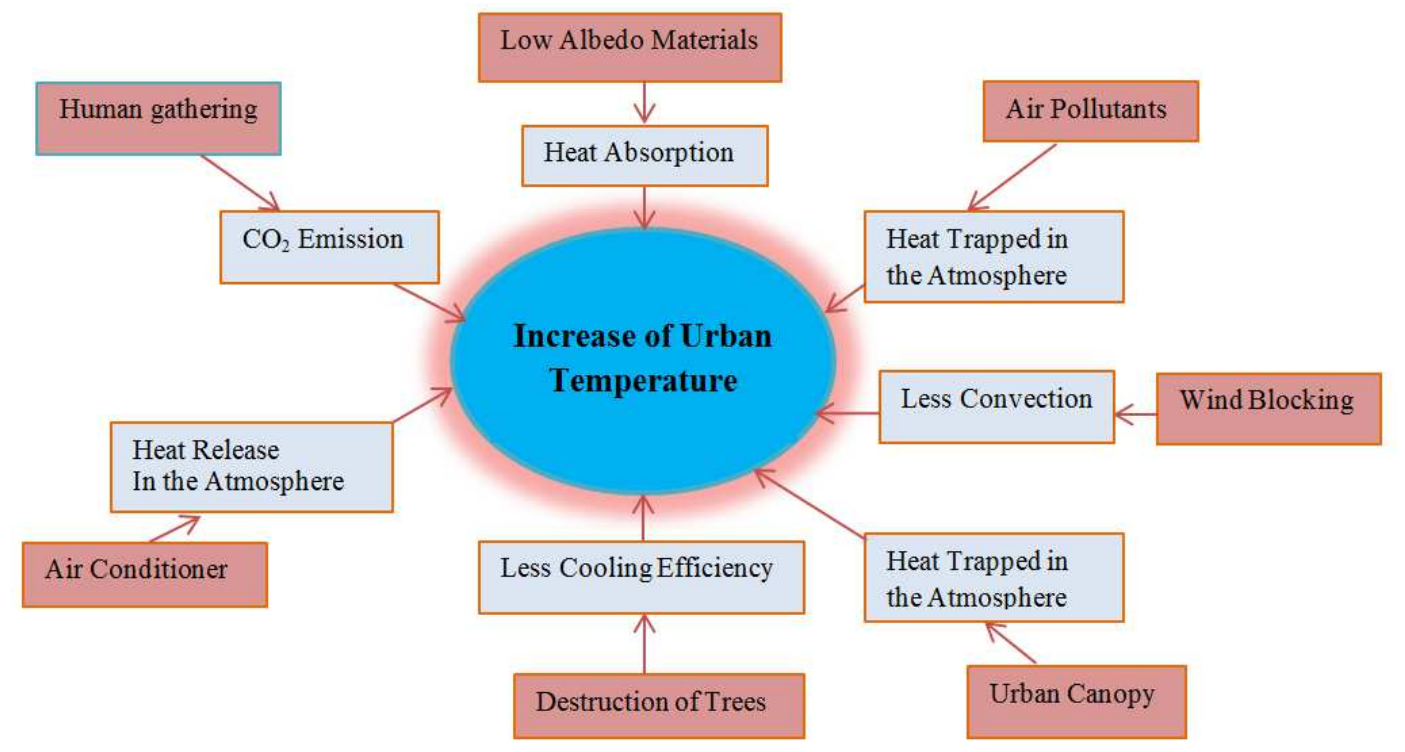

Figure 1. Process of Urban Heat Island (UHI) Formation. 


\subsection{Effects}

The effects are devastating in the summertime, especially in the tropical and arid regions. It causes discomfort to the people living in the middle of the city. Owing to the excessive heat people with little enduring capability undergo heat stress and it causes illness as well as death (Voogt 2004). Furthermore, the increased temperature will cause more energy required to cool the buildings to provide comfort to the people. This will augment the expenditure of the people and government as well. For every $1^{\circ} \mathrm{C}$ temperature increase, the energy demand may go up by $2-4 \%$ in the summertime (Akbari, 2001). Nonetheless, those people working outside of buildings or on the roads or in open places are the worst sufferers of the microclimate effect. As the demand for electricity soars, more fossil fuel is also burned causing high emission of green house gases to meet the demand tending to worsen the condition and decline of climate (Adinna 2009). At the same time, increased use of air conditioners leads to worsening of the effect even more. However, in the winter season, the UHI effect tends to give people comfort owing to the increased temperature (Shahmohamadi 2010; Voogt 2004; Mobaraki). The following figure illustrates how UHI affects human lives.

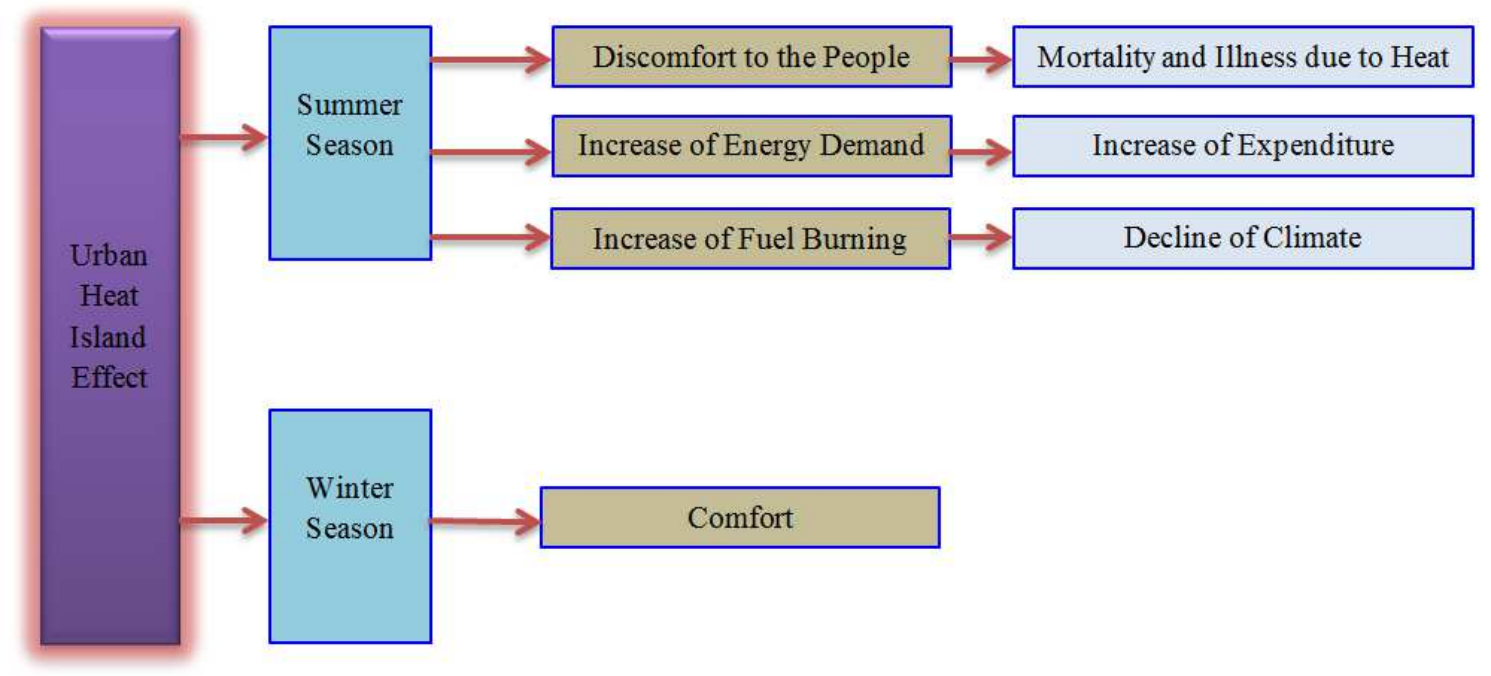

Figure 2. Effects of Urban Heat Island Formation.

\section{Literature Study}

Theeuwes (2012) measured the impact of green vegetation and water surfaces in the urban areas on UHI effect. They found that each $10 \%$ vegetative cover can reduce the temperature $0.6 \mathrm{~K}$ and commented that trees can reduce the effect substantially. However, they concluded that the existence of water bodies does not decrease the temperature; rather it increases the effect. LI et al. performed a case study by analyzing the heat environment of Tsinghua University to establish an urban planning approach. They suggested that enough space in between buildings and plantation of trees will be efficient to decrease the intensity of heat island. Adinna et al. (2009) assessed the impact of urban heat island effect in the Enugu city of Nigeria and suggested adaptive measures to keep the UHI effect under control in the city. Their study concluded that the use of high dense green vegetation, low absorptive roofing materials and lightening of pavement materials can reduce the effect in Enugu urban. Akbari et al. (2001) studied with the effect of cool surfaces and shade trees on the UHI effect. They found that surfaces with high albedo materials and urban trees have a significant contribution to reversing the heat island. In their paper, the cost reduction due to the mitigating measures of UHI effect is also calculated. According to Akbari et al. (2001), for every $1{ }^{0} \mathrm{C}$ increase of temperature, the electricity demand may rise by $2-4 \%$. On the other hand, $20 \%$ energy can be saved which is used for air conditioning if mitigation measures are taken in order to reduce the UHI effect. Yamamoto (2006) described several mitigation measures for UHI effect and also gave a description about some mitigation projects in Japan and other counties including the wind paths in Freiburg in Germany. He recommended some key mitigation measures like energy saving buildings and traffic systems, restoring green areas in urban areas and improvement of urban airflow.

Sadoudi et al. (2014) simulated three different strategies using ENVI-met to observe their usefulness to mitigate the UHI effect in Tehran. They considered the following three measures: (1) High Albedo Materials (HAM) (2) Vegetation and Green roofs (VEG) and (3) Combination of both of them (HYBRID). According to them HYBRID was the most effective mitigation measure as the result showed that it reduces the temperature of Tehran city by $4.2 \mathrm{~K}$ at daytime. On the other hand, only $0.5 \mathrm{~K}$ of cooling effect can be achieved at daytime by using HAM. Rosenweig et al. (2006) used regional climate model (MM5) combining meteorological data, satellite and GIS data to determine the 
influence of urban forestry, living roofs and light surfaces on UHI effect in the New York metropolitan area. They analyzed the New York City heat island effect model by taking six case study areas and tested the mitigation strategies. They found that vegetation helps to keep surfaces cool more effectively than increasing the albedo. But they suggested that in order to reduce the temperature in New York City, replacement of low albedo materials with high albedo light colored materials will work great as $64 \%$ of the surface area of the city can be replaced easily. Synnefa et al. (2008) studied the use of cool materials which are characterized by the high reflectivity to reveal the effect on urban heat island. A study was conducted using a mesoscale model (MM5, version 3-6-1) over the city of Athens, Greece. They considered two scenarios: a moderate and a large scale increase in albedo scenario. They concluded that use of high albedo materials in a massive scale can lower the temperature by $2^{0} \mathrm{C}$. Taha (1997) reviewed urban climate and urban heat islands. He illustrated characteristics of urban climate as well as various features of heat island such as causes and effects. After studying numerous literatures which are based on numerical simulation and field measurements, he commented that increasing albedo and vegetation cover prove to be effective to reduce both surface and air temperature substantially. The UHI effect of the Shiraz city of Iran which is booming as well as rapidly urbanizing has been studied by Mobaraki (2012). He analyzed the Shiraz city based on selected four districts around it. In his concluding remarks, he mentioned that the city should have greenery and high albedo materials to mitigate the microclimate effect.

\section{Strategies to Reduce Urban Heat Island}

According to Sailor (2006) the urban heat island effect mitigation can be done in two ways. One is by increasing the albedo of the urban surface and the other is by increasing evapotranspiration. However, the major strategies to mitigate the UHI effect are described below:

\subsection{High Albedo Roofing Materials}

Dark roofs absorb heat from the sunlight and make houses warm. In contrast, light colored roofs with similar insulation properties do not get warmed significantly by reflecting solar radiation (Akbari et al. 2001). So, the choice of roofing color can contribute to temperature reduction. Roofing materials with low albedo absorb solar heat and make the house warm which results in high consumption of energy for air conditioning. So, one of the mitigation strategies is to use high albedo roofing materials. If cool surfaces are achieved through changing color, it adds no extra cost to the roof (Bretz et al. 1998 and Rosenfeld et al. 1992). The EPDM materials which have a rubber like nature, have no impact on cost for change of color (Sailor 2006). Sailor (2006) suggests white materials which have albedo greater than 0.60 instead of black materials having albedo of 0.05 to 0.10 can be used as roofing materials. Bretz et al (1998), Akbari et al. (1998) and Konopacki et al. (1997) observed the effectiveness of albedo by using roofing materials of different albedo ranging from 0.20 to 0.60 and they found that the roof temperature dropped by $25^{0} \mathrm{C}$ for 0.60 albedo compared to that of 0.20 albedo. According Sailor, D. J. (2006) the action of convection of the roofing materials has a role to play to the effectiveness of UHI effect mitigation strategies. One of the problems which are incorporated with the reflective roofs is that the reflection capability lessens with age because of the soot (Berdahl et al. 2002). However, it can be easily compensated by cleaning it periodically. Again, for cool roofs, there is an issue of aesthetics. For commercial buildings, it is not a matter of headache, but in case of residential buildings, house owners tend to use deep colored roofs to make it look less dirty over the period of time (Bretz and Akbari 1994, 1997). On the other hand, cooling roofs glares at daytime. For a roof parallel to the street level, it is not to be considered. Nevertheless, a sloping roof may create enough glares to hamper the vision of drivers which may cause accidents (Bretz and Akbari 1994, 1997). So, the color of sloping cool roof should be selected by taking this into account.

\subsection{High Albedo Pavements}

More solar radiation could be reflected if the road and highway pavements were of high albedo materials (Akbari et al. 2001). So, proper selection of pavement materials can also contribute to the reduction of UHI effect. Levinson, \& Akbari, H. (2002) suggested some reflective concrete surfaces after curing various concrete mixes of albedo ranging from 0.41 to 0.77 . Sailor (2006) suggests that white cement mixtures can be made for which the albedo should be higher than the most reflective gray cement mixtures. However, use of high albedo materials for roads and highway pavement may not be so much effective because of the skyview factor. Even if, it is used, some of the reflection will be intercepted by the buildings surrounding it. In addition to it, a large proportion of it is covered by vehicles in most of the daytime. The problem of glaring which is associated with cooling roofs is also accompanied with the high albedo pavements. Sailor (2006) states that high albedo pavements may increase visibility at night, thus reduces the requirement of light. He continues that at day time glaring will have negative effect regarding visibility. Again, the wearing action will lessen the reflectivity of pavements within a very short time due to vehicle movement. So, Durability and visibility should also be taken into account before going to take the initiative.

\subsection{Green Vegetation}

Increasing the amount of vegetation is one of the most effective strategies to mitigate the effects of the urban microclimate. (Wilmers, 1988; Dimoudi and Nikolopoulou, 
2003; Synnefa et al., 2008; Takebayashi and Moriyama, 2009; Xua et al., 2010). This can be achieved by tree plantation both in residential and municipal tree plantation programs (Sailor 2006). Trees contribute to reducing the heat island effect by their evapotranspiration (Akbari et al. 2001; Dimoudi and Nikolopoulou 2003). Again, trees have a direct effect on reducing the UHI effect as it absorbs $\mathrm{CO}_{2}$ (Akbari et al. 2001). According to Robitu et al. 2006 and Pearlmutter et al. 2009 empirical derivations also demonstrated reduced temperature if green vegetation is applied. The statement is also backed by Steenveld et al. 2011 and Heusinkveld et al. 2012. In the heart of cities, as the human gathering is huge, the emission of huge amount $\mathrm{CO}_{2}$ leads to the increase of temperature. Increased number of trees will help to mitigate the condition by absorbing $\mathrm{CO}_{2}$. Theuwes et al. carried out an experiment in Rotterdem by using two tricycle equipped with instruments to measure $3 \mathrm{D}$ radiation components, temperature, humidity and wind speed. Their bike traverse supported the finding of the previous research. According to Theuwes et al. temperature usually decreases by $0.6 \mathrm{~K}$ for each $10 \%$ addition of vegetation. For this mitigation strategy, it should also be taken into account that trees hinder the natural flow of air within the urban areas (Heisler 1989). So, cooling breezes may not work effectively.

\subsection{Shade Trees}

Shade trees are those with a huge canopy and can provide protection to houses and pedestrians from direct sunlight keeping them comparatively cool. Shade trees also help to cut down the temperature by evapotranspiration process (Sailor 2006). In the United States, near about 200,000 shade trees were planted every year between 1992 and 1996 as a strategy to mitigate heat islands, protect climate, and improve air quality in urban areas (Scott et al. 1999). The principal role of shade trees is that sunlight is intercepted by it keeping the buildings comparatively cool (Akbari et al. 2001). It reduces the building air conditioning, lowers the air temperature and improves the air quality. Planting shade trees involve some sort of maintenances and cost pertaining to it. Estimation given by Akbari et al. (2001) states that the savings associated with the benefits of shade trees may be up to $\$ 200$ in its' entire life. And the maintenance cost may range between $\$ 10$ to $\$ 500$ per tree. At the same time, shade trees need several years to grow up and start protecting a building from severe heat. Shade trees are also vulnerable to extreme storms posing threat to human life (Sailor 2006). The routes of these trees may also affect the foundation of the adjacent buildings and streets. Again, there may not be enough space in a land property to plant a shade tree. This is a problem in densely populated countries like Bangladesh, India, China, etc. So, before going for this option, careful judgment should be made to handle all the situations properly.

\subsection{Pervious Pavements}

Impervious pavements do not allow water to infiltrate and cooling effect by evapotranspiration is not significant in this case (Sailor 2006). If the impermeable pavements are replaced with pervious pavements which will allow water to infiltrate, it can be expected that it will be able to reduce the temperature to a reasonable extent. Infiltrated water will help keep the pavement cool and directly affecting the temperature.

\subsection{Water Bodies}

Increased amount of water bodies may reduce temperature due to their evaporative action and enhanced wind speed is the opinion of Robitu et al. (2006). Again, as the heat absorption capacity of water is high, it will help to reduce the urban temperature. In contrast to this proposition, the bike traverse experiment by Theuwes et al. does not support this statement and opposes that it exacerbates the condition. The reason behind this was described as the high thermal inertia limits of water prevent nocturnal cooling once it is warmed. The stable nocturnal condition which limits the wind speed may also be another reason. So it is needed to investigate more whether extended water bodies in urban areas help to lower the temperature or not.

\subsection{Urban Planning}

Proper urban planning can also play a vital role in the mitigation of the UHI effect. Yamamoto (2006) has described an urban planning approach situated on the bank of river. His suggestion is to build the buildings in such a way that wind path is created for cool airflow from the river into the city. If buildings are built parallel to the direction of river, no airflow will occur in to the city. If the buildings are positioned at a $45^{\circ}$ angle, wind will get channel if it flows only in one direction. But if flows from the opposite direction, it cannot get away inside the city. However, airflow will occur in case the buildings are perpendicular to the river. $\mathrm{He}$ also mentioned that this option is expected to play a major role in the fore coming days and it deserves further attention. In other types of cities, it is expected that if there is sufficient amount of free space and channel to circulate the wind, it will help to minimize the effect of the urban microclimate.

\subsection{Green Roofs}

According to Wong (2005) roofs in the cities represent about $21 \%$ to $26 \%$ of the city area. So, if the roofs are made green by vegetating, it will act a major role in mitigating the UHI effect. Green roofs absorb heat and filter the air, keeping the temperature low (Getter 2006). Plants utilize heat energy to continue their evapotranspiration process, making the environment cool. In addition to it, green roofs help to delay the runoff duration which will keep the cities cooler for a longer period (Getter 2006). As it also absorbs water, it keeps itself cooler, helping to reduce the temperature. Again, green roofing will bring energy balance to the corresponding 
building by keeping the energy demand low.

The UHI effect mitigation strategies and how these

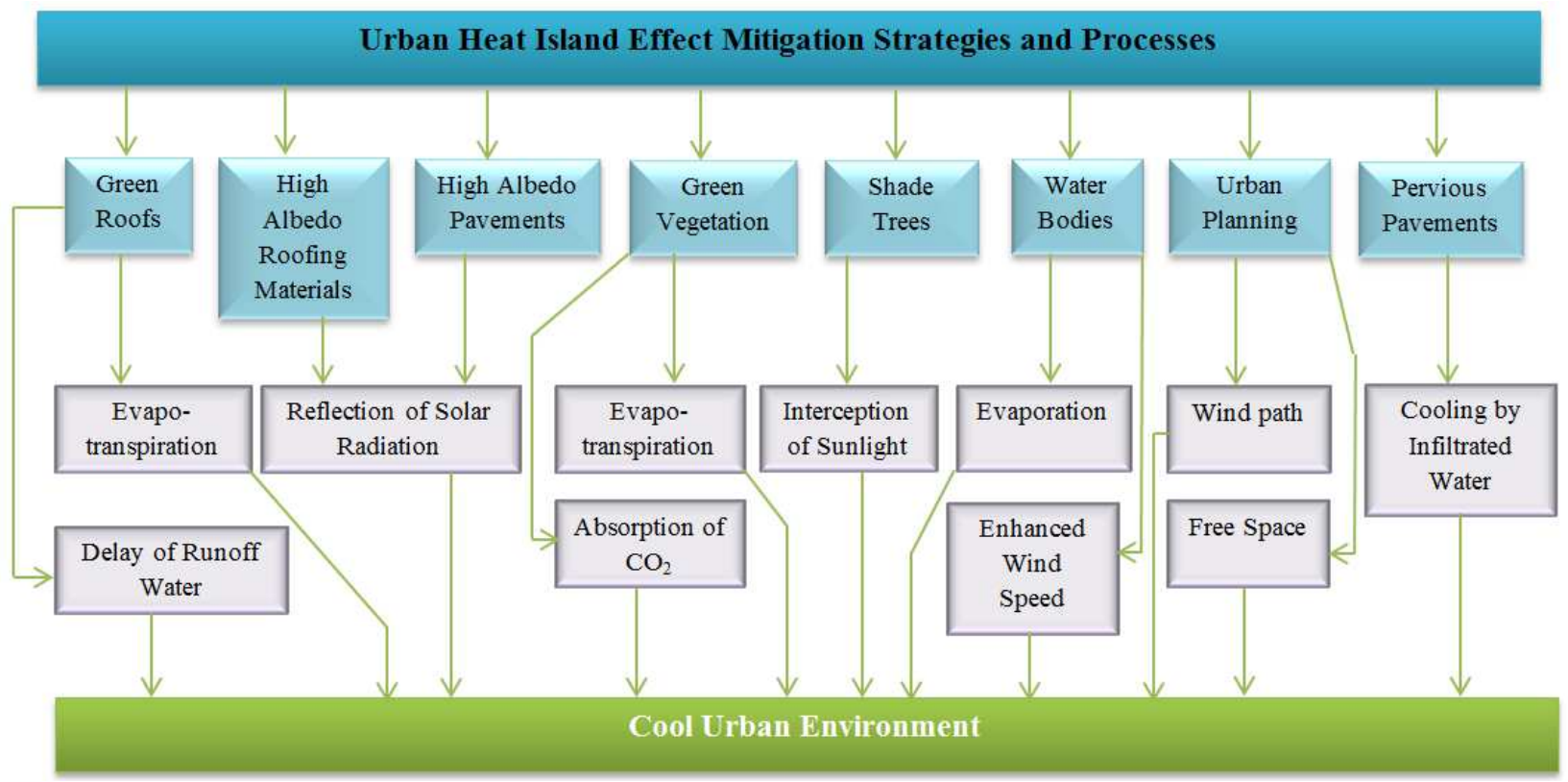

Figure 3. Urban Heat Island Effect Mitigation Strategies and Processes.

\section{Conclusion}

Among all the mitigation strategies, green vegetation seems to be the most effective measure to encounter UHI effect. Also, its effectiveness is well proven and widely accepted by the experts as a very much efficient mitigation measure. At the same time, it has a few drawbacks. However, cities where tree plantation in a large scale is not feasible, use of high albedo materials and pervious pavements may be adopted. Green roofs may play an important role in this case also. On the other hand, as a small scale mitigation measure, shade trees can be used where there is enough space in the house yard considering its' limitations. In growing cities, proper planning must have to be done to minimize the effect economically. Presence of water bodies in the city areas is a controversial issue to some researches and more researches should be carried out for this mitigation strategy. Use of high albedo pavement has numerous limitations and its effectiveness is not so much great. Thus, it should be taken as the last option for the UHI mitigation measure.

\section{References}

[1] Adinna, E., Christian, E. I., \& Okolie, A. T. (2009). Assessment of urban heat island and possible adaptations in Enugu urban using landsat-ETM. Journal of Geography and Regional Planning, 2(2), 030-036.

[2] Akbari, H., Gartland, L., \& Konopacki, S. (1998). Measured energy savings of light colored roofs: Results from three California demonstration sites: Lawrence Berkeley National Lab., Environmental Energy Technologies Div., Berkeley, CA (United States).
[3] Akbari, H., Pomerantz, M., \& Taha, H. (2001). Cool surfaces and shade trees to reduce energy use and improve air quality in urban areas. Solar energy, 70(3), 295-310.

[4] Berdahl, P., Akbari, H., \& Rose, L. S. (2002). Aging of reflective roofs: soot deposition. Applied optics, 41(12), 23552360 .

[5] Bousse, Y. S. (2009). Mitigating the urban heat island effect with an intensive green roof during summer in Reading, UK. Dissertação de Mestrado, University of Reading.

[6] Bouyer, J., Musy, M., Huang, Y., \& Athamena, K. (2009). Mitigating urban heat island effect by urban design: forms and materials. Paper presented at the Proceedings of the 5th urban research symposium, cities and climate change: responding to an urgent agenda, Marseille.

[7] Bretz, S., \& Akbari, H. (1994). Durability of high-albedo roof coatings and implications for cooling energy savings. Final report: Lawrence Berkeley Lab., CA (United States).

[8] Bretz, S., Akbari, H., \& Rosenfeld, A. (1998). Practical issues for using solar-reflective materials to mitigate urban heat islands. Atmospheric environment, 32(1), 95-101.

[9] Dimoudi, A., \& Nikolopoulou, M. (2003). Vegetation in the urban environment: microclimatic analysis and benefits. Energy and buildings, 35(1), 69-76.

[10] Getter, K. L., \& Rowe, D. B. (2006). The role of extensive green roofs in sustainable development. HortScience, 41(5), 1276-1285.

[11] Grimmond, C., \& Oke, T. R. (1999). Heat storage in urban areas: Local-scale observations and evaluation of a simple model. Journal of applied meteorology, 38(7), 922-940.

[12] Heisler, G. M. (1989). Effects of trees on wind and solar radiation in residential neighborhoods: Northeastern Forest Experiment Station, USDA Forest Service, Northeastern Research Station, Forest Resources Laboratory. 
[13] Heusinkveld, B. G., Van Hove, L., Jacobs, C., Steeneveld, G., Elbers, J., Moors, E., \& Holtslag, A. (2010). Use of a mobile platform for assessing urban heat stress in Rotterdam. Paper presented at the Proceedings of the 7 th Conference on Biometeorology.

[14] Konopacki, S., Akbari, H., \& Gartland, L. (1997). Cooling energy savings potential of light-colored roofs for residential and commercial buildings in 11 US metropolitan areas: Lawrence Berkeley Lab., CA (United States).

[15] Levinson, R., \& Akbari, H. (2002). Effects of composition and exposure on the solar reflectance of portland cement concrete. Cement and Concrete Research, 32(11), 1679-1698.

[16] LI, K., LIN, B., \& JIANG, D. A New Urban Planning Approach for Heat Island Study at the Community Scale.

[17] Masson, V. (2006). Urban surface modeling and the mesoscale impact of cities. Theoretical and Applied Climatology, 84(1-3), 35-45.

[18] Mobaraki, A. (2012). Strategies for Mitigating Urban Heat Island Effects in Cities: Case of Shiraz City Center. Eastern Mediterranean University (EMU).

[19] Oke, T. (1987). Boundary layer climates. 2nd. Methuen, 289p.

[20] Oke, T. R. (1982). The energetic basis of the urban heat island. Quarterly Journal of the Royal Meteorological Society, $108(455), 1-24$.

[21] Okwen, R., Pu, R., \& Cunningham, J. (2011). Remote sensing of temperature variations around major power plants as point sources of heat. International journal of remote sensing, 32(13), 3791-3805.

[22] Pearlmutter, D., Krüger, E., \& Berliner, P. (2009). The role of evaporation in the energy balance of an open-air scaled urban surface. International Journal of Climatology, 29(6), 911-920.

[23] Priyadarsini, R., Hien, W. N., \& David, C. K. W. (2008). Microclimatic modeling of the urban thermal environment of Singapore to mitigate urban heat island. Solar energy, 82(8), 727-745.

[24] Quattrochi, D. A., Luvall, J. C., Rickman, D. L., Estes, M. G., Laymon, C. A., \& Howell, B. F. (2000). A decision support information system for urban landscape management using thermal infrared data: Decision support systems. Photogrammetric Engineering and Remote Sensing, 66(10), 1195-1207.

[25] Robitu, M., Musy, M., Inard, C., \& Groleau, D. (2006). Modeling the influence of vegetation and water pond on urban microclimate. Solar energy, 80(4), 435-447.

[26] Rosenfeld, A., Akbari, H., Taha, H., \& Bretz, S. (1992). Implementation of light-colored surfaces: profits for utilities and labels for paints. Proceedings of the ACEEE 1992 Summer Study on Energy Efficiency in Buildings, 9, 141.

[27] Rosenzweig, C., Solecki, W., \& Slosberg, R. (2006). Mitigating New York City's heat island with urban forestry, living roofs, and light surfaces. A report to the New York State Energy Research and Development Authority.
[28] Sailor, D. J. (2006). Mitigation of urban heat islands-Recent progress and future prospects. Paper presented at the Paper presented on american meteorological society 6th symposium on the urban environment and forum on managing our physical and natural resources.

[29] Santamouris, M., Paraponiaris, K., \& Mihalakakou, G. (2007). Estimating the ecological footprint of the heat island effect over Athens, Greece. Climatic Change, 80(3-4), 265-276.

[30] Scott, K. I., Simpson, J. R., \& McPherson, E. G. (1999). Effects of tree cover on parking lot microclimate and vehicle emissions. Journal of Arboriculture, 25(3), 129-142.

[31] Shahmohamadi, P., Che-Ani, A., Ramly, A., Maulud, K., \& Mohd-Nor, M. (2010). Reducing urban heat island effects: A systematic review to achieve energy consumption balance. Paper presented at the Phys. Sci.

[32] Sodoudi, S., Shahmohamadi, P., Vollack, K., Cubasch, U., \& Che-Ani, A. (2014). Mitigating the Urban Heat Island Effect in Megacity Tehran. Advances in Meteorology, 2014.

[33] Steeneveld, G., Koopmans, S., Heusinkveld, B., Van Hove, L., \& Holtslag, A. (2011). Quantifying urban heat island effects and human comfort for cities of variable size and urban morphology in the Netherlands. Journal of Geophysical Research: Atmospheres (1984-2012), 116(D20).

[34] Synnefa, A., Dandou, A., Santamouris, M., Tombrou, M., \& Soulakellis, N. (2008). On the use of cool materials as a heat island mitigation strategy. Journal of Applied Meteorology and Climatology, 47(11), 2846-2856.

[35] Taha, H. (1997). Urban climates and heat islands: albedo, evapotranspiration, and anthropogenic heat. Energy and buildings, 25(2), 99-103.

[36] Takebayashi, H., \& Moriyama, M. (2009). Study on the urban heat island mitigation effect achieved by converting to grasscovered parking. Solar energy, 83(8), 1211-1223.

[37] Theeuwes, N., Steeneveld, G., Ronda, R., Heusinkveld, B., \& Holtslag, A. 197: Mitigation of the urban heat island effect using vegetation and water bodies.

[38] Voogt, J. A. (2004). Urban heat islands: hotter cities. America Institute of Biological Sciences.

[39] Wilmers, F. (1988). Green for melioration of urban climate. Energy and buildings, 11(1), 289-299.

[40] Wong, E. (2005). Green roofs and the Environmental Protection Agency's heat island reduction initiative. Paper presented at the Proc. of 3rd North American Green Roof Conference: Greening rooftops for sustainable communities, Washington, DC.

[41] Xu, J., Wei, Q., Huang, X., Zhu, X., \& Li, G. (2010). Evaluation of human thermal comfort near urban waterbody during summer. Building and environment, 45(4), 1072-1080.

[42] Yamamoto, Y. (2006). Measures to mitigate urban heat islands. Science and Technology Trends Quarterly Review, 18(1), 6583. 